\title{
2021 Caregiving Out-of-Pocket Study: Detailed Methodology
}

The sample consisted of qualified caregivers defined as those U.S. adults age 18 or older responding "Yes" to the following screener:

"Are you currently providing unpaid care to a relative or friend 18 years or older to help them take care of themselves?

This may include helping with personal needs or medication management, household chores, or transportation. It might be managing a person's finances, arranging for outside services, preparing meals or grocery shopping, helping with bathing or dressing, or even visiting regularly to see how they are doing. This adult need not live with you."

Among this sample, research was conducted using two related data sources (with all data being collected on-line between March 15-April 25, 2021 using Ipsos' national, probability-based online KnowledgePanel囚:

The primary data source was a month-long diary study of 2,380 qualified caregivers. Quota samples were established for Hispanic, African American and Asian American caregivers but their at-random incidence resulted in only minor disproportionate representation. Each of the diary study caregivers recorded expenses for one week. Recruitment for the diary study was from 4,220 qualified caregivers identified through an initial screener. Diary study participants did not differ in any systematic way from the remainder of qualified caregivers. The caregivers in the diary study coded each of their recorded caregiving expenses as falling into one of five differing caregiving expense categories (e.g. household expenses, medical expenses, etc. [see Table A1]).

Table A1. Dollar amounts and percentages represented by each of the five diary study expense categories (Diary study figures)

\begin{tabular}{|l|c|c|}
\hline 1. Household expenses & $\$ 3,791$ & $52 \%$ \\
\hline 2. Medical expenses & $\$ 1,225$ & $17 \%$ \\
\hline 3. Personal Care Item expenses & $\$ 768$ & $11 \%$ \\
\hline 4. Recreation/Education/Other expenses & $\$ 400$ & $6 \%$ \\
\hline 5. Caregiver personal expenses/respite & $\$ 1,058$ & $15 \%$ \\
\hline
\end{tabular}

* For tables, category descriptors are necessarily abbreviated. See Diary Study form for the expenses included in each expense category.

The secondary data source was a retrospective survey asking about caregiving outlays over the previous year for each of 30 (non-exhaustive) expense categories (see Table A2). The 
retrospective survey and the diary study have differing strengths. The diary study is better at capturing routine, often small costs within the study period as well as major expense that occur within the study period. The retrospective survey is not as good as the diary method at estimating the sum of small, routine costs, but is the only method for capturing large expenses that are not likely to have been observed during a diary study period (but that should be included in annual estimates).

\section{Blending raw diary study estimates and retrospective survey expenses}

The retrospective survey figures were used to detect one-time or relatively rare caregiving expenditures that would not be reliably captured in a shorter-run diary study component. To estimate the average annual caregiving expenditure for our sample, figures from the 2,380 caregivers providing both diary and retrospective survey data needed to be combined and then blended together. Below is a description of the approach adopted:

1) When blending diary expenses with retrospective survey expenses, there was a desire to maintain the error structure of the annualized diary study expenses (mainly by ending up with an overall expense figure with a similar standard deviation and distribution skew). The 30 individual retrospective survey categories feed into the five general expense categories of the diary study (see Table A2). This enables qualified expenses from each of the 30 retrospective survey expense categories to be included in the overall caregiver expense figure.

2) The expenses reported in the retrospective survey that qualified to be blended with diary study costs were determined by a process that first determined the share of diary study expenses that were likely to be observed on a monthly basis and then blending in non-recurring expenses (from the retrospective survey) so that annualized figures reflected a blend of routine, recurring expenses as well as expenses occurring at a differing interval (and not being captured in the diary study). The blending process involved weighting three annualized cost estimates based on three differing assumption - the high, the low and the realistic. The first was a 'high' assumption which assumes that few diary study expenses were recurring. This requires a high share of retrospective expenses to be blended, which would likely lead to erroneously high annualized estimates). The 'low' estimate assumes that relatively few retrospective expenses need to be blended into annualized cost estimates (likely generating an erroneously low annualized estimate of expenses. The 'realistic' assumption was empirically-based involving a review of the literal descriptions of purchases which included not only price and timing information but indications of the products' purpose and other contextual information. It was noted that relatively few diary transactions (14\% of purchases) were non-recurring in nature, but these few transactions represented $46 \%$ of expenses (a dynamic also observed in 2016 data). When the three assumptions were given relative weights (using a three-point estimation formula) it was estimated that $39 \%$ of expenses in the retrospective survey were wholly reduplicative with figures reported in the diary study component and were unqualified to be blended with diary study figures. To reassign these qualifying expenses from the retrospective survey to expenses in the study's diary component, a cross-walk between the five major costs categories in the diary study and the 30 expense categories reported to in the retrospective survey was conducted (see Table A2 for the cross-walk). 


\section{Table A2. Cost categories related to 30 specific caregiving expenses measured in the retrospective survey}

\begin{tabular}{|c|c|}
\hline & $\begin{array}{l}\text { Related Diary Study } \\
\text { expense category }\end{array}$ \\
\hline \multicolumn{2}{|l|}{ Retrospective survey figures } \\
\hline Personal Protection Equipment (PPE) for you or the person you care for. & Personal care items \\
\hline $\begin{array}{l}\text { Home modifications related to mobility/safety issues (e.g., installing ramps, } \\
\text { bathroom modifications, etc.) }\end{array}$ & Household \\
\hline Remote health and/or safety monitoring devices & Household \\
\hline Nursing home or long-term care facility fees & Medical \\
\hline Assisted living or other residential setting fees & Household \\
\hline Independent living/retirement community fees & Household \\
\hline Travel (includes airfare, trains, etc. as well as hotels, parking, gas, etc.) & Recreation/Education/Other \\
\hline Legal fees related to the caregiving situation & Recreation/Education/Other \\
\hline Relocation costs for you or the person you are caring for & Recreation/Education/Other \\
\hline $\begin{array}{l}\text { Major medical equipment such as a wheel chair, motorized scooter, special } \\
\text { bed, etc. }\end{array}$ & Medical \\
\hline Services such as home care aides, adult day services & Medical \\
\hline Medical, dental, or vision insurance premiums & Medical \\
\hline Long-term care insurance premiums & Medical \\
\hline Over-the-counter drugs & Medical \\
\hline Prescription drugs & Medical \\
\hline Medical supplies & Medical \\
\hline Incontinence supplies & Personal care items \\
\hline Nutritional supplements & Medical \\
\hline Caregiver support services such as geriatric care managers or counseling & $\begin{array}{l}\text { Caregiver personal } \\
\text { expenses/Respite }\end{array}$ \\
\hline Services such as household care (e.g. cleaning, lawn, home maintenance) & Housing \\
\hline Clothing for the person you care for & Personal care items \\
\hline Other housing payments such as rent, utilities, phone/computer service & Household \\
\hline Home repairs & Household \\
\hline Retrofitting vans or vehicles to accommodate wheel chairs & Recreation/Education/Other \\
\hline $\begin{array}{l}\text { Assistive technologies and devices (e.g., hearing aids, cognitive assistance } \\
\text { devices, etc.) }\end{array}$ & Medical \\
\hline $\begin{array}{l}\text { Transportation costs for the person you care for (e.g., gas, car maintenance, } \\
\text { ride share fees, etc.) }\end{array}$ & Household \\
\hline $\begin{array}{l}\text { Technology needed for video chat with the person you care for, remote health } \\
\text { monitoring, remote monitoring, or virtual health visits/telehealth (e.g., the } \\
\text { purchase of tablets, computers, smart phones, etc.) }\end{array}$ & Household \\
\hline $\begin{array}{l}\text { Digital memberships (e.g., Prime, etc.) entertainment platforms, digital } \\
\text { streaming services }\end{array}$ & Recreation/Education/Other \\
\hline Telephone or wireless devices for the person you care for & Recreation/Education/Other \\
\hline Cash given to the person you care for their choice on how to spend it & Recreation/Education/Other \\
\hline
\end{tabular}


Table A3: Composition of the average annual caregiver expense figure, by data source

\begin{tabular}{|l|c|c|}
\hline & Average annual expense & $\begin{array}{c}\text { Percent of total expenses } \\
\text { (by study component) }\end{array}$ \\
\hline Total expenses & $\$ \mathbf{7 , 2 4 2}$ & $100 \%$ \\
\hline Diary study expenses & $\$ 5,743$ & $79 \%$ \\
\hline Retrospective survey expenses & $\$ 1,499$ & $21 \%$ \\
\hline
\end{tabular}

\section{Measure of financial strain and other costs}

The raw dollar amounts devoted to caregiving do not account for the fact that the same caregiving expenses for a caregiver with a low annual income will prove more of a financial strain than the same caregiving expense would for a higher-income caregiver. For this reason, the following analysis will present caregiving expenses as raw dollar amounts and also as a percentage of a caregiver's annual income (given by: average annual caregiving expense divided by average annual household income). In terms of regarding the percentage measure as an indicator of financial strain, it should be noted that the higher the percentage of one's income devoted to caregiving, the less one has of their remaining income to devote to other expenses. 